\title{
Capillary electrophoresis for total glycosaminoglycan analysis
}

\author{
Ebru Ucakturk • Chao Cai • Lingyun Li • Guoyun Li • \\ Fuming Zhang $\cdot$ Robert J. Linhardt
}

Received: 22 March 2014 /Revised: 18 April 2014 / Accepted: 24 April 2014 /Published online: 11 May 2014

(C) Springer-Verlag Berlin Heidelberg 2014

\begin{abstract}
A capillary zone electrophoresis-laser-induced fluorescence detection (CZE-LIF) method was developed for the simultaneous analysis of disaccharides derived from heparan sulfate, chondroitin sulfate/dermatan sulfate, hyaluronan, and keratan sulfate. Glycosaminoglycans (GAGs) were first depolymerized with the mixture of GAG lyases (heparinase I,
\end{abstract}

Electronic supplementary material The online version of this article (doi:10.1007/s00216-014-7859-8) contains supplementary material, which is available to authorized users.

\section{R. J. Linhardt}

Department of Chemistry and Chemical Biology, Center for Biotechnology and Interdisciplinary Studies, Rensselaer Polytechnic Institute, Troy, NY 12180, USA

\section{R. J. Linhardt}

Department of Biology, Center for Biotechnology and Interdisciplinary Studies, Rensselaer Polytechnic Institute, Troy, NY 12180, USA

\section{R. J. Linhardt}

Department of Chemical and Biological Engineering, Center for Biotechnology and Interdisciplinary Studies, Rensselaer Polytechnic Institute, Troy, NY 12180, USA

\section{R. J. Linhardt $(\square)$}

Department of Biomedical Engineering, Center for Biotechnology and Interdisciplinary Studies, Rensselaer Polytechnic Institute, Troy, NY 12180, USA

e-mail: linhar@rpi.edu

E. Ucakturk $\cdot$ C. Cai $\cdot \mathrm{L}$. $\mathrm{Li} \cdot \mathrm{G}$. Li $\cdot$ F. Zhang

Department of Chemistry and Chemical Biology, Rensselaer

Polytechnic Institute, Troy, NY 12180, USA

\section{E. Ucakturk}

Department of Analytical Chemistry, Faculty of Pharmacy,

Hacettepe University, Sihhiye Ankara 06100, Turkey

G. Li

College of Food Science and Technology, Ocean University of China, Qingdao, Shandong 266003, China
II, III and chondroitinase $\mathrm{ABC}$ and chondroitinase AC II) and GAG endohydrolase (keratinase II) and the resulting disaccharides were derivatized by reductive amination with 2aminoacridone. Nineteen fluorescently labeled disaccharides were separated using $50 \mathrm{mM}$ phosphate buffer ( $\mathrm{pH} 3.3$ ) under reversed polarity at $25 \mathrm{kV}$. Using these conditions, all the disaccharides examined were baseline separated in less then $25 \mathrm{~min}$. This CZE-LIF method gave good reproducibility for both migration time $(\leq 1.03 \%$ for intraday and $\leq 4.4 \%$ for interday) and the peak area values $(\leq 5.6 \%$ for intra- and $\leq 8.69 \%$ for interday). This CZE-LIF method was used for profiling and quantification of GAG derivative disaccharides in bovine cornea. The results show that the current CZE-LIF method offers fast, simple, sensitive, reproducible determination of disaccharides derived from total GAGs in a single run.

Keywords Capillary electrophoresis · Biopolymers · Enzymes

\section{Introduction}

Glycosaminoglycans (GAGs) are linear, highly charged, anionic polysaccharides consisting of repeating disaccharides units and can be divided into four classes - heparan sulfate (HS)/heparin (HP), chondroitin sulfate (CS)/dermatan sulfate (DS), keratan sulfate (KS), and hyaluronan (HA). These classes differ in the structure of their repeating disaccharides and also in their biological functions [1]. They are widely represented on cell surfaces, inside cells, and in the extracellular matrix. GAGs, with the exception of hyaluronan, are biosynthesized as protein/GAG glycoconjugates known as proteoglycans. The biological functions of proteoglycans are principally determined by the structure of their GAG chains $[2,3]$. 
GAGs interact with hundreds of plasma proteins, including growth factors, cytokines, chemokines, proteases, protease inhibitors, coagulant and anticoagulant proteins, complement proteins, lipoproteins, and lipolytic enzymes. These interactions are critical in cell adhesion, proliferation, motility and differentiation, viral and bacterial infection, cancer, and inflammation $[4,5]$. Therefore, considerable attention has been focused on qualitative and quantitative analysis of GAGs to understand their biological importance.

Analysis of intact GAGs are challenging because they have a highly negative charge, a polydisperse and microheterogeneous structure, and a high molecular weight [6]. Therefore, instead of analyzing intact GAGs, analysis is usually performed after chemically or enzymatically depolymerizing GAGs to oligosaccharides or disaccharides. Knowing the structure and amount of each disaccharide or oligosaccharide unit can be useful for understanding the structure-activity relationship of GAGs [7, 8].

GAG-degrading enzymes are divided into two classesGAG lyases and GAG hydrolases. There are several common GAG-degrading endolytic lyases: (1) heparinases (I, II, and III), acting on HS and HP; (2) the chondroitinases (ABC and ACII) acting primarily on CS and DS; and (3) bacterial hyaluronidases acting primarily on HA. It is noteworthy that chondroitinases can act on linkages within HA and that bacterial hyaluronidases can act on linkages within CS [9]. GAGdegrading lyases eliminatively cleave glycosidic linkages between hexosamine and hexuronic acid residues, leaving a deoxy- $\alpha$-L-threo-hex-4-enopyranosyluronic acid ( $\Delta U A)$ residue at the nonreducing end of the newly formed product $[9$, $10]$.

GAG hydrolase enzymes act by hydrolytic mechanism to produce saturated residues at the products nonreducing ends. Keratanase and keratinase II are the GAG endohydrolases that depolomerize KS. Keratanase cleaves the internal $\beta 1-4$ galactosidic linkages in KS and generally affords oligosaccharides. In contrast, keratanase II cleaves $\beta 1-3$ glucosaminidic linkages to galactose, as well as those in KS to galactose-6sulfate, releasing monosulfated or disulfated disaccharides from KS [11].

Following GAG depolymerization, the separation of disaccharide product often relies on strong anion exchange, reversed-phase, reversed-phase ion-pair, normal phase, high-performance liquid chromatography (HPLC) and hydrophilic interaction chromatography, capillary electrophoresis (CE), and fluorophore-assisted carbohydrate electrophoresis [12-42]. Mass spectrometry, ultraviolet and fluorescence detection methods are then used for analyte detection and quantification. Enzymatic depolymerization of all GAGs, with the exception KS, results in products containing a $\Delta \mathrm{UA}$ residue at their nonreducing end, making these detectable in the ultraviolet (UV) at $232 \mathrm{~nm}\left(\varepsilon_{\mathrm{M}} \sim 3,000-5,000\right)$. However, the analysis of the low quantities of GAGs, present in a small number of cells, requires higher detection sensitivity. Therefore, precolumn or postcolumn derivatization is frequently used in disaccharide analysis [21-41]. These derivatization methods not only enhance detection sensitivity but can also improve disaccharide separations [43]. A number of fluorophores, including 2-cyanoacetamide [26], 2-aminobenzoic acid [27, 37], 4,4-difluoro-4-bora-3a,4a-diaza-s-indacene hydrazide derivatives [28], 2-aminopyridine [29], 2-aminoacridone (AMAC) [22-25, 30-36], 7-aminonaphthalene-1,3-disulfonic acid [39], and 8-aminonaphthalene-1,3,6-trisulfonic acid [41] are commonly used for labeling GAG-derived disaccharides.

$\mathrm{CE}$ is a powerful technique that has some advantages over other chromatographic approaches, such as high separation efficiency, rapid analysis, relatively simple instrumentation, and low sample consumption. CE, combined with laser-induced fluorescence (LIF) detector, becomes a very sensitive method for the disaccharide analysis. LIF detection of AMAC-derivatized GAG disaccharides is up to 100 -fold more sensitive than UV detection of the nonderivatized GAG disaccharides at $232 \mathrm{~nm}$ [32]. Disaccharides derived from CS/DS, HS/ $\mathrm{HP}$, and HA are typically analyzed by CE-UV or CELIF in a separate CE experiments [30-42]. This requires multiple, repetitive, and tedious sample preparation steps, including GAG extraction from biological sample, GAG depolymerization, disaccharide labeling, and disaccharide analysis. These multiple analytical procedures results in lost time, lost sample, reduced sensitivity, and higher costs.

There is a recent report that uses CZE-LIF for the simultaneous analysis of 17 AMAC-labeled CS/DS, HA, and HS disaccharides [30]. In this report, the total analysis time is more than $60 \mathrm{~min}$ and also disaccharides derived from KS were not determined. The only method, which has been used for the simultaneous analysis of KS, HS/HP, and CS/DS disaccharides in a single run, relies on liquid chromatography tandem mass spectrometry (LC-MS-MS), and this method only resolved a seven-component mixture of $\mathrm{NS}_{\mathrm{HS}}, 0 \mathrm{~S}_{\mathrm{HS}}$, $6 \mathrm{~S}_{\mathrm{HS}}, 4 \mathrm{~S}_{\mathrm{CS}}, 6 \mathrm{~S}_{\mathrm{CS}}, 2 \mathrm{~S}_{\mathrm{KS}}$, and $\mathrm{NS}_{\mathrm{KS}}$ (see Table 1 for disaccharide structures) [20].

The aim of the current study is to develop a reproducible, fast, simple, and sensitive CZE-LIF method for the profiling and the quantification of the disaccharides derived from HS (8 major), CS/DS (8 major), HA (1), and KS (2 major) in a single CZE run and to show the applicability of this method to a biological sample that contains a similarly complex mixture of GAGs. Such a CZE-LIF method should be useful for the rapid profiling and quantification of the total GAGs in glycomics studies and improves our understanding the biological role of GAGs in biology. 
Table 1 LOQ and coefficient of determination $\left(r^{2}\right)$ for 19 AMAClabeled disaccharides $\triangle U A$ 4-deoxy- $\alpha$-L-threohexenopyranosyluronic acid, GlcN N-acetyl glucopyransose, GalN N-acetylgalactopyransose, Gal galactopyranose, $A c$ acetyl, $S$ sulfo, $L O Q$ limit of quantification

\begin{tabular}{|c|c|c|c|c|}
\hline Disaccharides & Abbrev. & $\begin{array}{l}\text { LOQ } \\
\left(\text { ng } \mu L^{-1}\right)\end{array}$ & $\begin{array}{l}\text { Linearity range } \\
\left(\operatorname{ng} \mu \mathrm{L}^{-1}\right)\end{array}$ & $\begin{array}{l}\text { Coefficient of } \\
\text { determination }\left(r^{2}\right)\end{array}$ \\
\hline \multicolumn{5}{|l|}{ HS/HP disaccharides } \\
\hline$\Delta \mathrm{UA}(1-4) \mathrm{GlcNAc}$ & $0 \mathrm{~S}_{\mathrm{HS}}$ & 0.1 & $0.1-15$ & 0.999 \\
\hline$\Delta \mathrm{UA}(1-4) \mathrm{GlcNS}$ & $\mathrm{NS}_{\mathrm{HS}}$ & 0.5 & $0.5-20$ & 0.999 \\
\hline$\Delta \mathrm{UA}(1-4) \mathrm{GlcNS} 6 \mathrm{~S}$ & $6 \mathrm{~S}_{\mathrm{HS}}$ & 0.1 & $0.1-15$ & 0.998 \\
\hline$\Delta \mathrm{UA} 2 \mathrm{~S}(1-4) \mathrm{GlcNAc}$ & $2 \mathrm{~S}_{\mathrm{HS}}$ & 0.1 & $0.1-15$ & 0.999 \\
\hline$\Delta \mathrm{UA}(1-4) \mathrm{GlcNS} 6 \mathrm{~S}$ & $\mathrm{NS}_{6 \mathrm{HS}}$ & 0.5 & $0.5-20$ & 0.993 \\
\hline$\Delta \mathrm{UA} 2 \mathrm{~S}(1-4) \mathrm{GlcNS}$ & $2 \mathrm{SNS}_{\mathrm{HS}}$ & 0.1 & $0.1-15$ & 0.995 \\
\hline$\Delta \mathrm{UA} 2 \mathrm{~S}(1-4)$ GlcNAc6S & $2 \mathrm{~S}_{6} \mathrm{~S}_{\mathrm{HS}}$ & 0.1 & $0.1-15$ & 0.997 \\
\hline$\Delta \mathrm{UA} 2 \mathrm{~S}(1-4) \mathrm{GlcNS} 6 \mathrm{~S}$ & $\operatorname{TriS}_{\mathrm{HS}}$ & 0.5 & $0.5-20$ & 0.997 \\
\hline \multicolumn{5}{|l|}{ HA disaccharide } \\
\hline$\Delta \mathrm{UA}(1-3) \mathrm{GlcNAc}$ & HA & 0.1 & $0.1-15$ & 0.999 \\
\hline \multicolumn{5}{|l|}{ CS/DS disaccharides } \\
\hline$\Delta \mathrm{UA}(1-3) \mathrm{GalNAc}$ & $0 \mathrm{~S}_{\mathrm{CS}}$ & 0.1 & $0.1-15$ & 0.999 \\
\hline$\Delta \mathrm{UA}(1-3)$ GalNAc4S & $4 \mathrm{~S}_{\mathrm{CS}}$ & 0.1 & $0.1-15$ & 0.997 \\
\hline$\Delta \mathrm{UA}(1-3)$ GalNAc6S & $6 \mathrm{~S}_{\mathrm{CS}}$ & 0.1 & $0.1-15$ & 0.996 \\
\hline$\Delta \mathrm{UA2S}(1-3)$ GalNAc & $2 \mathrm{~S}_{\mathrm{CS}}$ & 0.1 & $0.1-15$ & 0.999 \\
\hline$\Delta \mathrm{UA} 2 \mathrm{~S}(1-3) \mathrm{GalNAc} 4 \mathrm{~S}$ & $\mathrm{SB}_{\mathrm{CS}}$ & 0.1 & $0.1-15$ & 0.999 \\
\hline$\triangle \mathrm{UA2S}(1-3)$ GalNAc6S & $\mathrm{SD}_{\mathrm{CS}}$ & 0.1 & $0.1-15$ & 0.998 \\
\hline$\Delta \mathrm{UA}(1-3)$ GalNAc4S6S & $\mathrm{SE}_{\mathrm{CS}}$ & 0.1 & $0.1-15$ & 0.999 \\
\hline$\Delta \mathrm{UA} 2 \mathrm{~S}(1-3)$ GalNAc4S6S & $\operatorname{Tris}_{C S}$ & 0.1 & $0.1-15$ & 0.998 \\
\hline \multicolumn{5}{|l|}{ KS disaccharides } \\
\hline Gal(1-4)GlcNAc6S & $\mathrm{NS}_{\mathrm{KS}}$ & 0.1 & $0.1-15$ & 0.996 \\
\hline Gal6S(1-4)GlcNAc6S & $2 \mathrm{~S}_{\mathrm{KS}}$ & 0.1 & $0.1-15$ & 0.999 \\
\hline
\end{tabular}

\section{Materials}

Bovine corneas were from Pel-freeze Biological (Rodgers, AR, USA). Actinase $\mathrm{E}$ was from Kaken Biochemicals (Tokyo, Japan). Keratan sulfate ( $\mathrm{Na}$ salt from bovine cornea) and keratanase II (from Bacillus sp. Ks 36) were purchased from Seikagaku Corporation (Japan). Keratanase II was dissolved in water and stored at $-80^{\circ} \mathrm{C}$ for up to 6 months. Unsaturated disaccharides standards of CS $(0 \mathrm{~S}, \Delta \mathrm{UA}-\mathrm{GalNAc} ; 4 \mathrm{~S}, \Delta \mathrm{UA}-$ GalNAc4S; 6S, $\Delta$ UA-GalNAc6S; 2S, $\Delta$ UA2S-GalNAc; $2 \mathrm{~S} 4 \mathrm{~S}$ or SB, $\triangle \mathrm{UA} 2 \mathrm{~S}-\mathrm{GalNAc} 4 \mathrm{~S}$; $2 \mathrm{~S} 6 \mathrm{~S}$ or SD, $\triangle \mathrm{UA} 2 \mathrm{~S}-$ GalNAc6S; 4S6S or SE, $\triangle \mathrm{UA}-$ GalNAc4S6S; and TriS,

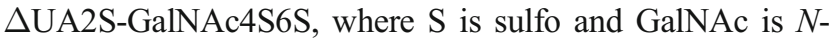
acetyl-D-galactosamine), unsaturated disaccharides standards of heparan sulfate (0S, $\triangle \mathrm{UA}-\mathrm{GlcNAc}$; NS, $\Delta \mathrm{UA}-$ GlcNS; $6 \mathrm{~S}$, $\triangle$ UA-GlcNAc6S; 2S, $\triangle$ UA2S-GlcNAc; 2SNS, $\triangle \mathrm{UA2S}-$ GlcNS; NS6S, $\triangle$ UA-GlcNS6S; 2S6S, $\triangle$ UA2S-GlcNAc6S; and TriS, $\triangle \mathrm{UA2S}-$ GlcNS6S, where GlcNAc is $N$-acetyl-Dglucosamine) and unsaturated disaccharides standard of hyaluronan ( $\triangle \mathrm{UA}-\mathrm{GlcNAc})$ were obtained from Seikagaku (Japan). Internal standard disaccharide $\triangle \mathrm{UA} 2 \mathrm{~S}$ $\mathrm{GlcNCOCH}_{2} \mathrm{CH}_{3} 6 \mathrm{~S}$ (where $\mathrm{COCH}_{2} \mathrm{CH}_{3}$ in propanoyl) was from Iduron, Manchester, UK. Recombinant heparin lyase I, II, and III from Flavobacterium heparinum were expressed in our laboratory in Escherichia coli strains, provided by Professor Jian Liu (University of North Carolina, College of Pharmacy, Chapel Hill, NC, USA). The heparinases were stored at $-80{ }^{\circ} \mathrm{C}$ in $10 \%(v / v)$ glycerol for up to 6 months. Chondroitin lyase ABC from Proteus vulgaris and chondroitin lyase ACII from Arthrobacter aurescens was from Seikagaku Corporation (Tokyo, Japan). The chondroitinases were reconstituted with water and stored at $-80^{\circ} \mathrm{C}$ for up to 6 months. AMAC $(\geq 98.0 \%)$ and sodium cyanoborohydride $(\geq 95.0 \%$ ) was supplied from Sigma (St. Louis, MO, USA). All other chemicals were of reagent grade. Vivapure Q Mini H columns were from Sartorius Stedium Biotech (Bohemia, NY, USA). Amicon ultracentrifugal filters (YM-10; 1000 molecular weight cut-off) were from Millipore (Billerica, MA, USA).

\section{Recovery of bovine corneal GAGs}

A bovine cornea was cut into the small pieces and individually subjected to proteolysis at $55{ }^{\circ} \mathrm{C}$ with $10 \%(w / v)$ of actinase E $(20 \mathrm{mg} / \mathrm{mL}$ in HPLC-grade water, Kaken Biochemicals, Tokyo, Japan) for 2 days at $\mathrm{pH}$ 6.0. After proteolysis, particulates were removed from the resulting solution by centrifugation at $12,000 \times \mathrm{g}$ for $5 \mathrm{~min}$. The supernatant was then concentrated 
using Microcon YM-10 centrifugal filter units (10 kDa molecular weight cutoff, Millipore) by centrifugation at $12,000 \times \mathrm{g}$ and washed with $15 \mathrm{ml}$ of distilled water to remove peptides and salts. The retentate was collected and lyophilized and dissolved in $0.5 \mathrm{ml}$ of $8 \mathrm{M}$ urea containing $2 \%$ CHAPS $(\mathrm{pH}$ 8.3) and then loaded to Vivapure Q Mini H column (Bohemia, NY, USA) equilibrated with $200 \mu \mathrm{L}$ of $8 \mathrm{M}$ urea containing $2 \%$ CHAPS ( $\mathrm{pH} 8.3$ ) and put under centrifugal force $(700 \times g)$. The columns were then washed with $200 \mu \mathrm{L}$ of $8 \mathrm{M}$ urea containing $2 \% \mathrm{CHAPS}$ at $\mathrm{pH} 8.3$, followed by two washes with $200 \mu \mathrm{L}$ of $200 \mathrm{mM} \mathrm{NaCl}$. GAGs were released from the column by washing three times with $450 \mu \mathrm{L}$ of $16 \%$ $\mathrm{NaCl}$ and then collected eluent was desalted using YM-10 spin column $(12,000 \times g)$. Finally, the desalted GAGs $(\sim 15.0 \mathrm{mg})$ were lyophilized.

\section{Breakdown of GAGs to disaccharide products}

A portion of the recovered GAGs from bovine cornea $(\sim 100 \mu \mathrm{g})$ were depolymerized using the enzyme mixture of heparinase I, II, and III ( $5 \mathrm{mU}$ each $/ 20 \mu \mathrm{L})$, chondroitinase $\mathrm{ABC}$ and chondroitinase AC II $(5 \mathrm{mU}$ each/ $20 \mu \mathrm{L})$, and keratanase II $(5 \mathrm{mU} / 20 \mu \mathrm{L})$ in $100 \mu \mathrm{L} 100 \mathrm{mM}$ ammonium acetate $(2 \mathrm{mM}$ calcium chloride, $\mathrm{pH} 7.5)$ at $37^{\circ} \mathrm{C}$ for $10 \mathrm{~h}$ [20]. The enzymes used to digest the $5.0 \mathrm{mg}$ of GAGs were each in $>50$-fold excess to that required to completely digest a standard mixture of the same quantity of each GAG. The enzymatic products were then passed through the YM-10 spin columns $(12,000 \times g)$ for $5 \mathrm{~min}$ then were freeze-dried for AMAC labeling reaction.

\section{Derivatization of disaccharides with AMAC}

The freeze-dried bovine corneal samples containing GAGderived disaccharides or disaccharide standards were redissolved in $5 \mu \mathrm{L}$ of $0.1 \mathrm{M}$ AMAC in acetic acid/dimethyl sulfoxide (DMSO) $(3: 17, v / v)$ and left at room temperature for $30 \mathrm{~min}$. After that, $5 \mu \mathrm{L}$ of $1 \mathrm{M} \mathrm{NaBH}_{3} \mathrm{CN}$ was added to the reaction mixture and mixture was incubated at $45^{\circ} \mathrm{C}$ for $4.5 \mathrm{~h}$ [34]. Finally, bovine cornea sample containing AMAClabeled GAGs were diluted to various concentrations using DMSO/water $(50: 50 ; v / v)$, and then CE-LIF or LC-MS analysis was performed.

\section{CZE-LIF analysis of AMAC labeled disaccharides}

CZE analyses of the AMAC-labeled disaccharides were carried out HPCE system (Agilent Technologies, Wilmington, DE, USA) coupled with a ZETALIF laser induced fluorescent detector (Picometrics, Toulouse, France). All CZE experiments were performed using bare-fused silica capillary (Agilent, $50 \mu \mathrm{m}$ i.d. $\times 60 \mathrm{~cm}, 45 \mathrm{~cm}$ to detector). Each new capillary was conditioned before it was used. This conditioning procedure is necessary to ensure fully and uniformly charged capillary surface. A new capillary was rinsed with methanol (20 min), water (5 min), $1 \mathrm{M} \mathrm{HCl}(20 \mathrm{~min})$, water $(5 \mathrm{~min}), 1 \mathrm{M} \mathrm{NaOH}(15 \mathrm{~min})$ water $(5 \mathrm{~min}), 0.1 \mathrm{M} \mathrm{NaOH}$ (20 $\mathrm{min})$, water $(5 \mathrm{~min})$, and operating buffer $(10 \mathrm{~min})$. The capillary was also preconditioned (optimized procedure 3 ) with $0.1 \mathrm{M} \mathrm{HCl}$ (3 min), $0.1 \mathrm{M} \mathrm{NaOH}$ (7 min), HPLC-grade water (4 $\mathrm{min})$, and operating buffer $(5 \mathrm{~min})$ before each new set of runs. After each day of use, the capillary was rinsed with water for $5 \mathrm{~min}$ and then dried with air for $2 \mathrm{~min}$ to extend of the lifetime of capillary. Sodium phosphate buffer $(50 \mathrm{mM}$, $\mathrm{pH}$ 3.3) was used as operating buffer, and the separations were carried out at $25^{\circ} \mathrm{C}$ by applying $25 \mathrm{kV}$ voltage. The sample was injected hydrodynamically by the application of a pressure of 50 mbar for $5 \mathrm{~s}$.

\section{HPLC-MS analysis of AMAC-labeled disaccharides}

HPLC-MS analyses were performed on an Agilent 1200 LC/ MSD instrument (Agilent Technologies, Inc.) equipped with a 6300 ion trap and a binary pump. The column used was a Poroshell $120 \mathrm{C} 18$ column $(2.1 \times 150 \mathrm{~mm}, 2.7 \mu \mathrm{m}$, Agilent $)$ at $45^{\circ} \mathrm{C}$. Eluent A was $80 \mathrm{mM}$ ammonium acetate solution and eluent B was methanol. Eluent A and $15 \%$ eluent B were flowed $(150 \mu \mathrm{L} / \mathrm{min})$ through the column for $5 \mathrm{~min}$ followed by a linear gradient from 15 to $30 \%$ solution B from 5 to $30 \mathrm{~min}$. The column effluent entered the electrospray ionization MS source for continuous detection by MS. The electrospray interface was set in negative ionization mode with a skimmer potential of $-40.0 \mathrm{~V}$, a capillary exit of $-40.0 \mathrm{~V}$, and a source temperature of $350{ }^{\circ} \mathrm{C}$, to obtain the maximum abundance of the ions in a full-scan spectrum (150 $1,200 \mathrm{Da})$. Nitrogen $(8 \mathrm{~L} / \mathrm{min}, 40 \mathrm{psi})$ was used as a drying and nebulizing gas [21].

\section{Results and discussion}

Major disaccharides were obtained by enzymatic digestion of HS/HP, CS/DS, HA, and KS. The enzymatic digestion using heparinase I, II, and III afford eight major unsaturated disaccharides for $\mathrm{HS} / \mathrm{HP}$, chondroitinase $\mathrm{ABC}$, chondroitinase $\mathrm{AC}$ II affords eight major unsaturated disaccharides for CS/DS and one major unsaturated disaccharide for HA and keratanase II affords two major saturated disaccharides for KS [30, 20, 40] (see Table 1 for structures). The HS/HP, CS/ DS, and HA disaccharides are all commercially available as standards. The KS disaccharides were prepared from purified bovine corneal KS [19, 20]. 
The disaccharides were next labeled with AMAC by reductive amination. The aldehyde (hemiacetal) group at the reducing end of each disaccharide is coupled with amino group of AMAC, leading to the formation of a Schiff base intermediate which is immediately reduced to a stable secondary amine linkage using sodium cyanoborohydride. The derivatization involves a simple one-step procedure and can be monitored using CE with ultraviolet detection at $232 \mathrm{~nm}$ or using CZE-LIF $\lambda_{\mathrm{ex}}=425, \lambda_{\mathrm{em}}=530$. Moreover, in contrast to many other labeling reagents that need to be removed before analysis, excess AMAC is not detrimental in CZE analysis [21-26, 30-36].

A number of CZE methods have previously been developed for the analysis of CS/DS or HS or HA derivative disaccharides that afford excellent resolution, efficient separation, and short analysis times. Typically, CZE can resolve these negatively charged disaccharides using either low $\mathrm{pH}$ operating buffers $(\mathrm{pH} 3.0$ or 3.5) under reversed polarity or in high $\mathrm{pH}$ operating buffers ( $\mathrm{pH} 8.0$ to 10.4 , with or without additives) under normal polarity [30-39].

Our laboratory relied on $50 \mathrm{mM}$ phosphate buffer $(\mathrm{pH} 3.5)$ under reversed polarity at $25 \mathrm{kV}$ to successfully separate AMAC-labeled HS and CS disaccharides in a single run.
Under reversed polarity conditions AMAC-labeled disaccharides move through the capillary in groups, first tri-, then di-, mono-, and finally nonsulfated disaccharides. This elution order is particularly useful in investigating the sulfation patterns of GAGs present in biological samples. GAG-derived disaccharides contain different negative charge density and polarity due to their anionic carboxyl and $O$-sulfo and $N$-sulfo groups. CZE can also separate different disaccharides having identical net charge (i.e., TriS $_{\mathrm{HS}}$ and $\mathrm{TriS}_{\mathrm{CS}}$ ) due to differences in their molecular shapes. The nonsulfated disaccharides move slowly in the capillary and define the length of time required for disaccharide analysis [31]. KS, the least studied of the GAGs, has structural similarities to chondroitin sulfates but also contains the unique feature of having a galactopyranose residue instead of a pyranosyluronic acid residue. While there have been some efforts to separate CS and KS GAGs using agarose-gel electrophoresis and size exclusion chromatography it is often quite difficult to separate and analyze mixtures of these two GAGs $[44,45]$.

We next turned our attention to the simultaneous determination of the AMAC derivatives of KS, HS/HP, CS/DS, and HA disaccharides. Their simultaneous analysis was first attempted using CZE-LIF method (50 $\mathrm{mM}$ phosphate buffer,
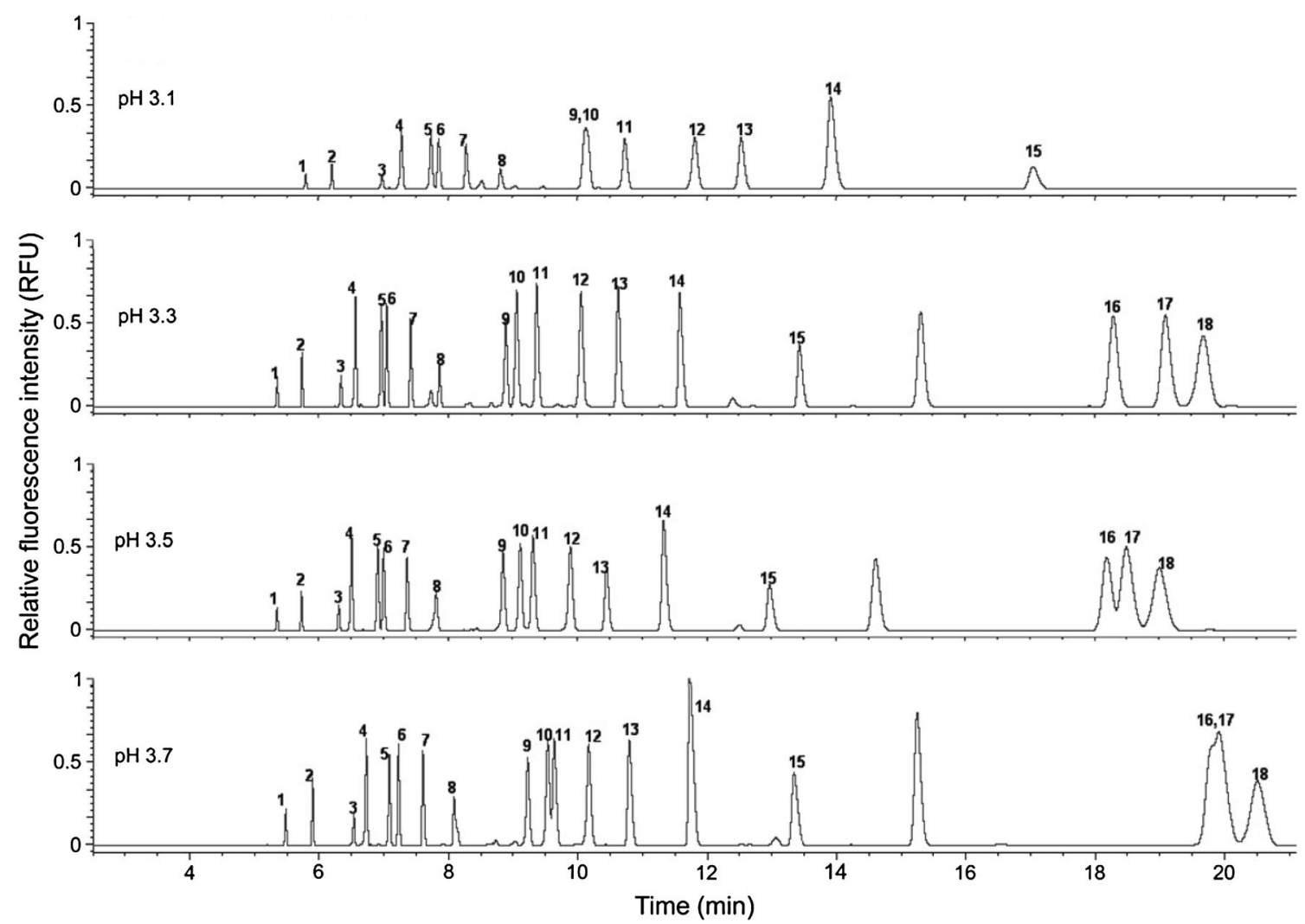

Fig. 1 Effect of phosphate buffer $\mathrm{pH}(3.1,3.3,3.5,3.7)$ on electropherograms of disaccharides derived from $\mathrm{HS}, \mathrm{CS} / \mathrm{DS}, \mathrm{HA}$ and $\mathrm{KS}$. TriS $\mathrm{CS}$ (1), $\operatorname{TriS}_{\mathrm{HS}}(\mathbf{2}), \mathrm{SD}_{\mathrm{CS}}(\mathbf{3}), \mathrm{SB}_{\mathrm{CS}}(4), \mathrm{SE}_{\mathrm{CS}}(\mathbf{5}), 2 \mathrm{~S}_{\mathrm{HS}} \mathrm{HS}(\mathbf{6}), \mathrm{NS}_{2} \mathrm{~S}_{\mathrm{HS}}(7)$, $\mathrm{NS} \mathrm{S}_{\mathrm{HS}}(\mathbf{8}), 2 \mathrm{~S}_{\mathrm{CS}}(\mathbf{9}), 2 \mathrm{~S}_{\mathrm{KS}}(\mathbf{1 0}), 6 \mathrm{~S}_{\mathrm{CS}}(\mathbf{1 1}), 4 \mathrm{~S}_{\mathrm{CS}}(\mathbf{1 2}), 2 \mathrm{~S}_{\mathrm{HS}}(\mathbf{1 3}), 6 \mathrm{~S}_{\mathrm{HS}}$ (14), $\mathrm{NS}_{\mathrm{HS}}(\mathbf{1 5}), \mathrm{NS}_{\mathrm{KS}}(\mathbf{1 6}), 0 \mathrm{~S}_{\mathrm{CS}}(\mathbf{1 7})$, and HA (18). Excess AMAC migrates as a peak between $\mathrm{NS}_{\mathrm{HS}}(\mathbf{1 5})$ and $\mathrm{NS}_{\mathrm{KS}}(\mathbf{1 6})$. The concentration of disaccharide mixture is $5 \mathrm{ng} \mathrm{LL}^{-1}$. Operating conditions in CZE-LIF: $50 \mathrm{mM}$ phosphate buffer $(\mathrm{pH} \mathrm{3.1,3.3,3.5,3.7)}$ in reversed polarity at $25 \mathrm{kV}$, injection time $5 \mathrm{~s} \mathrm{(50} \mathrm{mbar)}$ 
$\mathrm{pH} 3.5$, under reversed polarity at $25 \mathrm{kV}$ ) previously developed for separating HS/HP and CS/DS disaccharides [30]. Although baseline separation of disulfated KS disaccharide (10) from disulfated CS disaccharides $(\mathbf{9}, \mathbf{1 1})$ was achieved under these operating conditions, the resolution between nonsulfated CS (17), and monosulfated KS (16) was not satisfactory $\left(R_{s}=0.95\right)$. Several parameters, including $\mathrm{pH}$ and ionic strength of the operating buffer were next investigated to improve the resolution.

First, the impact of the phosphate buffer $\mathrm{pH}$ on resolution was investigated. The $\mathrm{p} K_{\mathrm{a}}$ values of GAG derivative disaccharide carboxyl groups vary slightly from one another, therefore, small differences in the $\mathrm{pH}$ of operating buffer close to their $\mathrm{p} K_{\mathrm{a}}$ values can impact the separation of HS and CS disaccharides [36]. For example, the control of buffer $\mathrm{pH}$ can reduce the time required for the separation of CS and HS disaccharides. The electropherograms of AMAC-labeled disaccharides over the $\mathrm{pH}$ range from 3.1 to 3.7 are shown in Fig. 1. As the $\mathrm{pH}$ increased, the resolution between monosulfated KS disaccharide (16) and nonsulfated CS disaccharide (17) decreased with both disaccharides completely overlapped at $\mathrm{pH}$ 3.7. Also, as the $\mathrm{pH}$ increased the disulfated
KS disaccharide (10) moved between being completely overlapped with $2 \mathrm{~S}_{\mathrm{CS}}$ disaccharide (9) at $\mathrm{pH} 3.1$ to being completely overlapped with $6 \mathrm{~S}_{\mathrm{CS}}$ disaccharide (11) at $\mathrm{pH}$ 3.7. These results show that buffer $\mathrm{pH}$ is one of the critical parameters for resolving AMAC-labeled KS and CS disaccharides. Therefore, $\mathrm{pH} 3.3$, giving the optimal separation within a $30 \mathrm{~min}$ period, was selected for further studies. It is noteworthy that peak intensity changes with changing $\mathrm{pH}$, which is consistent with previously reported data on $\mathrm{pH}$ mediated stacking of anions in CE [46].

Next, the effect of the ionic strength of the operating buffer on separation was examined by varying the buffer concentration from 30 to $60 \mathrm{mM}$ (Fig. 2). The results of these experiments demonstrated that operating buffer concentration contributed little, except in the resolution between $\mathrm{SE}_{\mathrm{CS}}(\mathbf{5})$ and $2 \mathrm{~S}_{6} \mathrm{~S}_{\mathrm{HS}}(6)$. Resolution between these two disaccharides was optimal using $50 \mathrm{mM}$ operating buffer, which was selected as buffer concentration for all further experiments. Thus, by using $50 \mathrm{mM}$ phosphate buffer $(\mathrm{pH} 3.3)$ under reversed polarity at $25 \mathrm{kV}$ the 19 AMAC-labeled disaccharides derived from HS/HP, CS/DS, HA and KS could be baseline-separated in less than $25 \mathrm{~min}$.
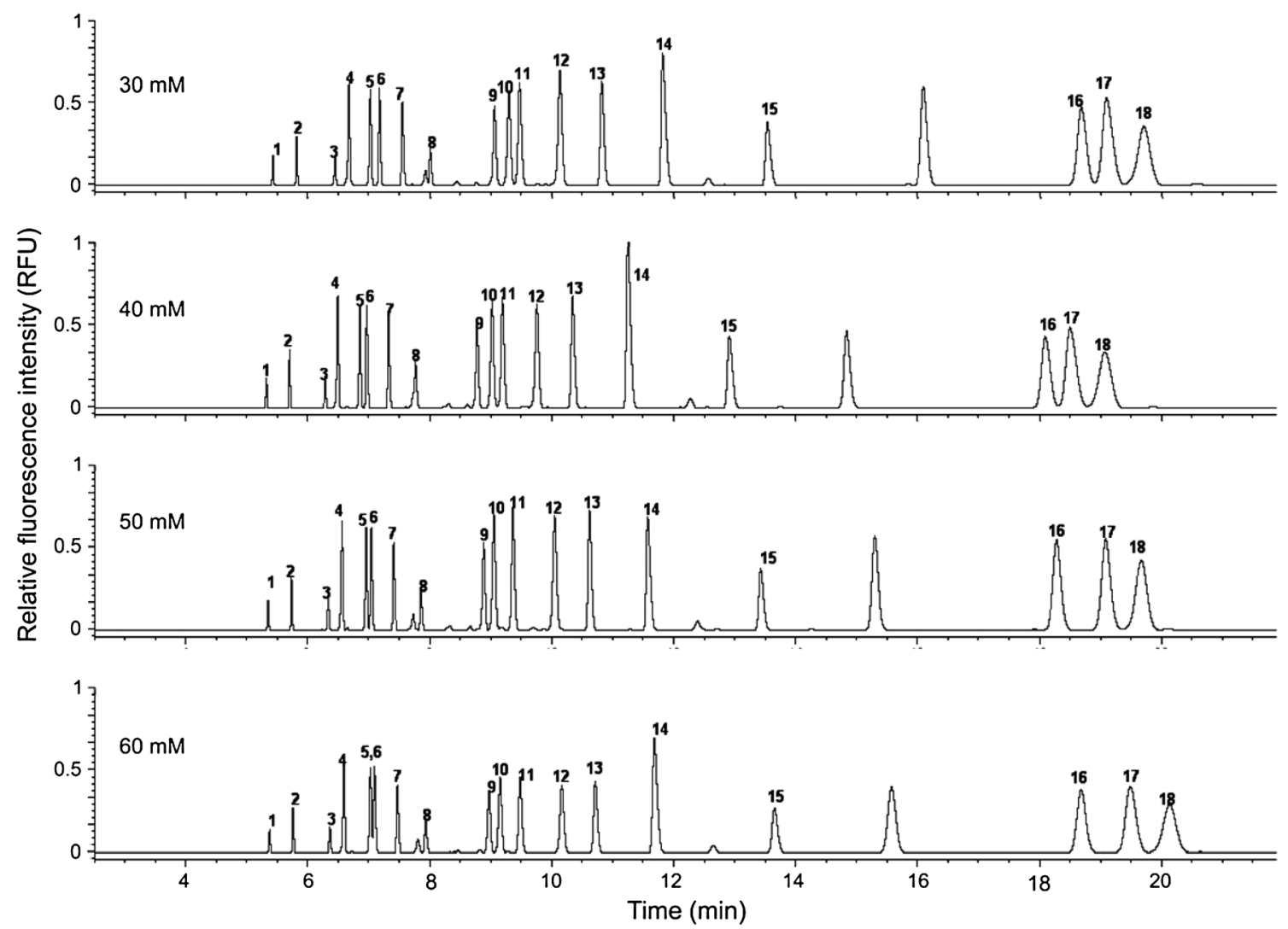

Fig. 2 Effects of phosphate buffer concentration on CZE-LIF separation

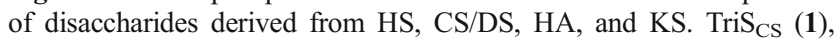
$\mathrm{TriS}_{\mathrm{HS}}(\mathbf{2}), \mathrm{SD}_{\mathrm{CS}}(\mathbf{3}), \mathrm{SB}_{\mathrm{CS}}(\mathbf{4}), \mathrm{SE}_{\mathrm{CS}}(\mathbf{5}), 2 \mathrm{~S}_{6} \mathrm{~S}_{\mathrm{HS}}(6), \mathrm{NS}_{2} \mathrm{~S}_{\mathrm{HS}}(7)$, $\mathrm{NS} \mathrm{S}_{\mathrm{HS}}(\mathbf{8}), 2 \mathrm{~S}_{\mathrm{CS}}(\mathbf{9}), 2 \mathrm{~S}_{\mathrm{KS}}(\mathbf{1 0}), 6 \mathrm{~S}_{\mathrm{CS}}(\mathbf{1 1}), 4 \mathrm{~S}_{\mathrm{CS}}(\mathbf{1 2}), 2 \mathrm{~S}_{\mathrm{HS}}(\mathbf{1 3}), 6 \mathrm{~S}_{\mathrm{HS}}$ (14), $\mathrm{NS}_{\mathrm{HS}}(\mathbf{1 5}), \mathrm{NS}_{\mathrm{KS}}(\mathbf{1 6}), 0 \mathrm{~S}_{\mathrm{CS}}(\mathbf{1 7})$, and HA (18). Excess AMAC migrates as a peak between $\mathrm{NS}_{\mathrm{HS}}(\mathbf{1 5})$ and $\mathrm{NS}_{\mathrm{KS}}(\mathbf{1 6})$. The concentration of disaccharide mixture is $5 \mathrm{ng} \mu \mathrm{L}^{-1}$. Operating conditions in CZE-LIF$3040,50,60 \mathrm{mM}$ phosphate buffer ( $\mathrm{pH} 3.3$ ) in reversed polarity at $25 \mathrm{kV}$, injection time $5 \mathrm{~s}$ (50 mbar) 


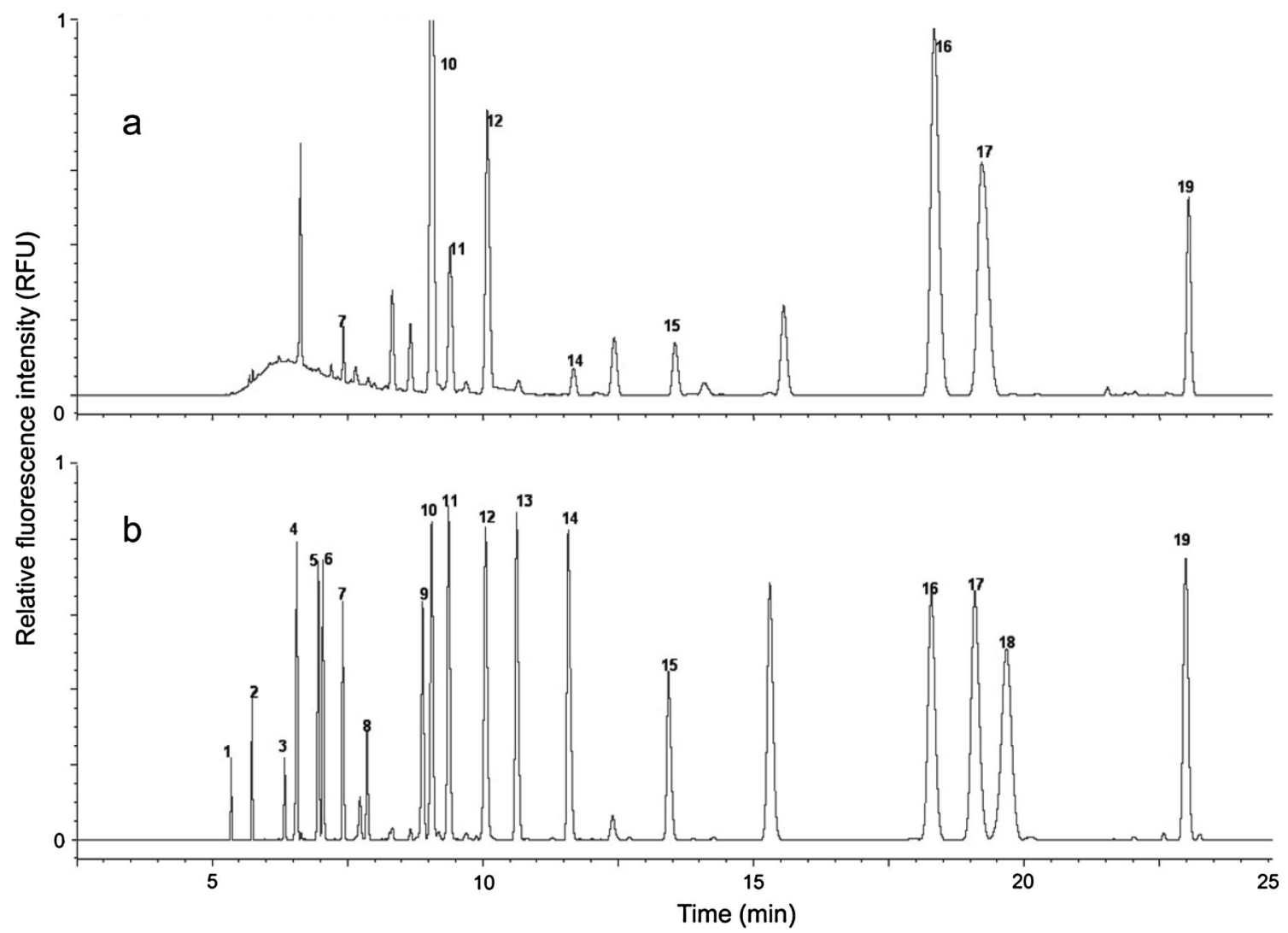

Fig. 3 Electropherograms of a bovine cornea sample (a) and disaccharide standard mixture (b) $\left(5 \mathrm{ng} \mu \mathrm{L}^{-1}\right.$ for each disaccharide). TriS $\mathrm{CS}_{\mathrm{CS}}(\mathbf{1})$, $\operatorname{TriS}_{\mathrm{HS}}$ (2), $\mathrm{SD}_{\mathrm{CS}}(\mathbf{3}), \mathrm{SB}_{\mathrm{CS}}(\mathbf{4}), \mathrm{SE}_{\mathrm{CS}}(\mathbf{5}), 2 \mathrm{~S}_{6} \mathrm{~S}_{\mathrm{HS}}(\mathbf{6}), \mathrm{NS}_{2} \mathrm{~S}_{\mathrm{HS}}$ (7), $\mathrm{NS} \mathrm{S}_{\mathrm{HS}}(\mathbf{8}), 2 \mathrm{~S}_{\mathrm{CS}}(\mathbf{9}), 2 \mathrm{~S}_{\mathrm{KS}}(\mathbf{1 0}), 6 \mathrm{~S}_{\mathrm{CS}}(\mathbf{1 1}), 4 \mathrm{~S}_{\mathrm{CS}}(\mathbf{1 2}), 2 \mathrm{~S}_{\mathrm{HS}}(\mathbf{1 3}), 6 \mathrm{~S}_{\mathrm{HS}}$

\section{Reproducibility of the CE-LIF method}

Fresh operating buffer was used for each analysis to prevent from buffer depletion and also preconditioning step was applied to capillary before each analysis. This afforded reproducible migration times for 19-AMAC labeled disaccharides
(14), $\mathrm{NS}_{\mathrm{HS}}(\mathbf{1 5}), \mathrm{NS}_{\mathrm{KS}}(\mathbf{1 6}), 0 \mathrm{~S}_{\mathrm{CS}}(\mathbf{1 7}), \mathrm{HA}(\mathbf{1 8})$, and $0 \mathrm{~S}_{\mathrm{HS}}(\mathbf{1 9})$. Operating conditions in CZE-LIF: $50 \mathrm{mM}$ phosphate buffer ( $\mathrm{pH} 3.3$ ) in reversed polarity at $25 \mathrm{kV}$, injection time $5 \mathrm{~s}(50 \mathrm{mbar})$

in the CZE. A preconditioning step between consecutive runs was necessary to achieve reproducible migration times. This preconditioning step cleanses and equilibrates the capillary surface and ensures a consistent electroosmotic flow. Three different preconditioning procedures were investigated to improve the reproducibility of the migration time of 19-AMAC

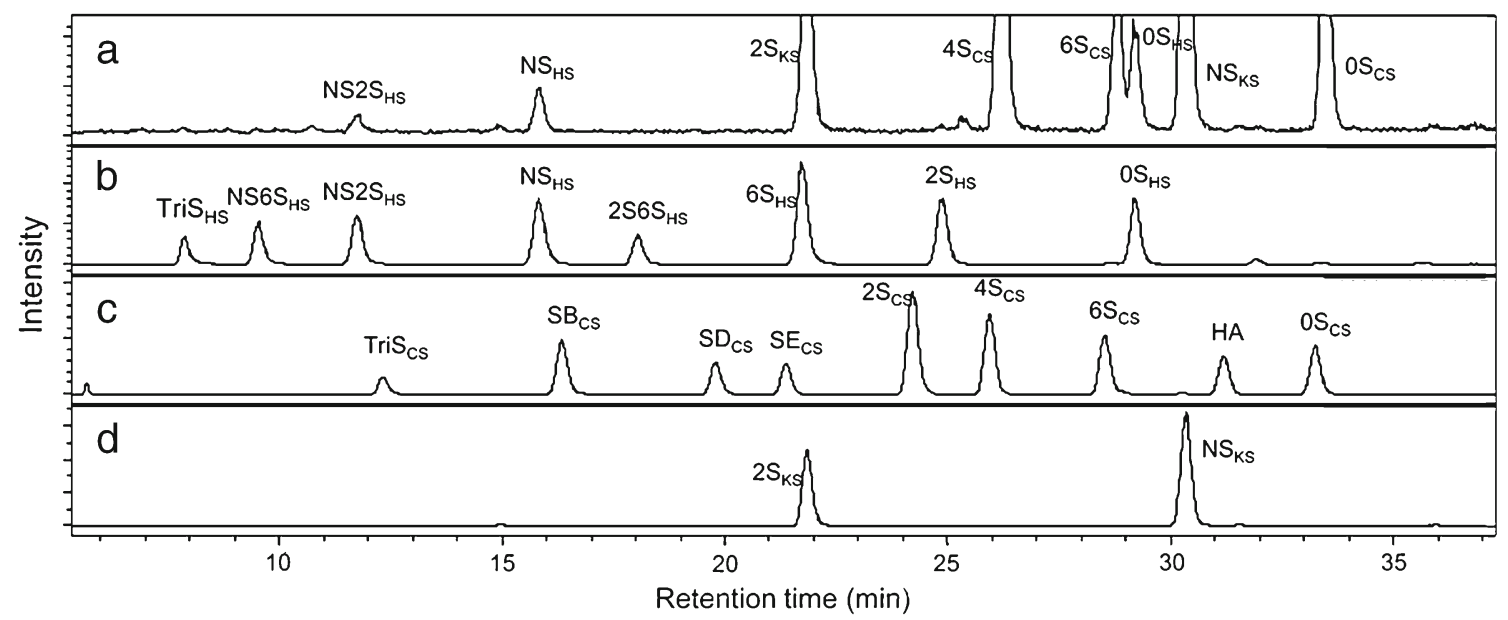

Fig. 4 LC-MS chromatogram of a bovine cornea sample (a) and HS (b), CS (c), and KS (d) disaccharide standards 
labeled disaccharides. The results show that preconditioning procedures 2 and 3 gives the similar relative standard deviation (RSD) value for some disaccharides $\left(2 \mathrm{~S}_{6} \mathrm{~S}_{\mathrm{HS}}, \mathrm{NS}_{2} \mathrm{~S}_{\mathrm{HS}}\right.$, $2 \mathrm{~S}_{\mathrm{HS}}, \mathrm{NS}_{\mathrm{HS}}, \mathrm{SB}_{\mathrm{CS}}, 4 \mathrm{~S}_{\mathrm{CS}}, 2 \mathrm{~S}_{\mathrm{KS}}$ ). However, preconditioning procedure 3 resulted in the best migration time reproducibility for all disaccharides except $\mathrm{NS}_{\mathrm{KS}}$ but the RSD value for this disaccharide is very reasonable $(0.6 \%)$ (see Electronic supplementary material Fig. S1). Under these conditions, the reproducibility of migration times for each disaccharide gives a RSD of $\leq 1.03 \%$. Also, interday reproducibility of migration times was found between 2.3 and $4.4 \%$ using the same capillary and under the same operating conditions.

Intraday and interday reproducibility of the CZE-LIF method were also evaluated at three different concentrations (1, 5, $15 \mathrm{ng} \mu \mathrm{L}^{-1}$ ) for each disaccharide and the interday reproducibility experiments were performed over five consecutive days. The results show that the intraday reproducibility did not exceed $5.6 \%$, while the interday reproducibility varied between 4.15 and $8.69 \%$.

Response linearity was determined using six concentrations and a calibration curve was constructed by plotting the peak area of disaccharides as a function of disaccharide concentration. The limit of quantification (LOQ) and correlation for the determination of each disaccharide is shown in Table 1. The calibration curve had a coefficient of determination $\left(r^{2}\right)$ value greater than 0.993 , which indicates a linear fit between disaccharide concentration and response.

\section{Analysis of GAGs composition (HS, CS/DS, HA, and KS) in bovine cornea}

The applicability of this CZE-LIF method to a biological sample was next examined by analyzing the bovine corneal tissue samples. GAGs were first extracted from bovine cornea. Cornea was selected, as it is one of the few tissues known to be relatively rich in KS [47]. We followed an extraction procedure established in our laboratory for the quantitative recovery of GAGs from cells, tissues (including cornea), and biological fluids, which relies on the use of strong anion exchange (SAX) spin columns [48, 49]. After extraction of GAGs from bovine cornea, GAGs were digested with the mixture of heparinase I, II, and III, chondroitinase ABC, chondroitinase ACII, and keratinase II. The resulting disaccharides were AMAC-labeled and analyzed using our CZE-LIF method (Fig. 3). The results show that bovine cornea contained 9 different disaccharides: $0 \mathrm{~S}_{\mathrm{HS}}(\mathbf{1 9}), \mathrm{NS}_{\mathrm{HS}}(\mathbf{1 5}), 6 \mathrm{~S}_{\mathrm{HS}}(\mathbf{1 4})$, $2 \mathrm{SNS}_{\mathrm{HS}}(\mathbf{7}), 4 \mathrm{~S}_{\mathrm{CS}}(\mathbf{1 1}), 6 \mathrm{~S}_{\mathrm{CS}}(\mathbf{1 2}), 0 \mathrm{~S}_{\mathrm{CS}}(\mathbf{1 7}), \mathrm{NS}_{\mathrm{KS}}(\mathbf{1 6})$, and $2 \mathrm{~S}_{\mathrm{KS}}(\mathbf{1 0})$. The weight percentages of these disaccharides was determined to be $0.8,0.7,0.1,0.6,5.9,3.2,5.1,11.7$, and $71.8 \%$, respectively. We had initially used external standard calibration to quantify the disaccharides in bovine cornea. Next, the use of an internal standard calibration was examined. A major issue encountered in using internal standard calibration curve for the disaccharide analysis is associated with finding the right internal calibrant. We first examined an AMAC-labeled unnatural disaccharide, $\triangle \mathrm{UA} 2 \mathrm{~S}-$ GlcNCOEt6S, as internal standard, but it comigrated with other AMAC-labeled disaccharides interfering with our analysis. Ultimately, we decided to use one of the disaccharides missing in the bovine cornea, AMAC-labeled $\operatorname{TriS}_{\mathrm{cs}}$, as our internal standard. The results obtained using a calibration curve based on internal standard was not significantly different $(p>0.05)$ from our external calibration curve. To further validate this analysis, the same sample was also analyzed by LC-MS (Fig. 4). The results showed that LC-MS and CZELIF methods gave comparable results, suggesting that the proposed CZE-LIF method can be accurately applied for the total GAG determination of bovine cornea. In addition to the use of an external standard calibration curve, an internal standard or standard addition method can be used for the identification and quantification of disaccharides. Standard addition methods such as spiking an authentic disaccharide standard into the sample is particularly helpful for the identification of closely migrating disaccharides in complex biological samples.

\section{Conclusions}

A fast, reproducible, simple, and sensitive CZE-LIF method was developed for the simultaneous profiling and quantification of major disaccharides derived from HS, CS/DS, HA, and $\mathrm{KS}$ in biological samples. This CZE-LIF method afforded the complete separation of 19 AMAC-labeled disaccharides within $25 \mathrm{~min}$. This CZE-LIF method when applied to determination of total GAGs in bovine cornea gave results that compared well with LC-MS analysis. On the basis of these results, we propose the use of CZE-LIF for analysis of total GAG amounts in cornea as well as in the other tissues.

Acknowledgments We acknowledge the Scientific and Technical Research Council of Turkey (TUBITAK, 2219-International Postdoctoral Research Scholarship Program). This research was also funded by the National Institutes of Health grants HL096972 and HL62244.

\section{References}

1. Ly M, Laremore TN, Linhardt RJ (2010) Proteoglycomics: recent progress and future challenges. Omics 14(4):389-399

2. Hileman RE, Fromm JR, Weiler JM, Linhardt RJ (1998) Glycosaminoglycan-protein interactions: definition of consensus sites in glycosaminoglycan binding proteins. BioEssays 20:156-167

3. Linhardt RJ, Toida T (2004) Role of glycosaminoglycans in cellular communication. Acc Chem Res 37:431-438

4. Capila I, Linhardt RJ (2002) Heparin-protein interactions. Angew Chem Int Ed Engl 41:391-412 
5. Kreuger J, Spillmann D, J-p L, Lindahl U (2006) Interactions between heparan sulfate and proteins: the concept of specificity. J Cell Biol 174:323-327

6. Yang B, Solakyildirim K, Chang Y, Linhardt RJ (2011) Hyphenated techniques for the analysis of heparin and heparan sulfate. Anal Bioanal Chem 399(2):541-557

7. Fu L, Zhang F, Li G, Onishi A, Bhaskar U, Sun P, Linhardt RJ (2014) Structure and activity of a new low molecular weight heparin produced by enzymatic ultrafiltration. J Pharm Sci 103:1375-1383

8. Xu Y, Wang Z, Liu R, Bridges AS, Huang X, Liu J (2012) Directing the biological activities of heparan sulfate oligosaccharides using a chemoenzymatic approach. Glycobiology 22(1):96-106

9. Linhardt RJ, Galliher PM, Cooney CL (1986) Polysaccharide lyases. Appl Biochem Biotechnol 12:135-176

10. Jandik KA, Gu K, Linhardt RJ (1994) Action pattern of polysaccharide lyases on glycosaminoglycans. Glycobiology 4(3):289-296

11. Ohmori J, Nawa Y, Yang D, Tsuyama S, Murata F (1999) Keratan sulfate glycosaminoglycans in murine eosinophil-specific granules. J Histochem Cytochem 47(4):481-488

12. Galeotti F, Volpi N (2013) Novel reverse-phase ion pair-high performance liquid chromatography separation of heparin, heparan sulfate and low molecular weight-heparins disaccharides and oligosaccharides. J Chromatogr A 1284:141-147

13. Wang B, Buhse LF, Al-Hakim A, Boyne Ii MT, Keire DA (2012) Characterization of currently marketed heparin products: analysis of heparin digests by RPIP-UHPLC-QTOF-MS. J Pharm Biomed Anal 67-68:42-50

14. Yang B, Weyers A, Baik JY, Sterner E, Sharfstein S, Mousa SA, Zhang F, Dordick JS, Linhardt RJ (2011) Ultra-performance ionpairing liquid chromatography with on-line electrospray ion trap mass spectrometry for heparin disaccharide analysis. Anal Biochem 415:59-66

15. Brustkern AM, Buhse LF, Nasr M, Al-Hakim A, Keire DA (2010) Characterization of currently marketed heparin products: reversedphase ion-pairing liquid chromatography mass spectrometry of heparin digests. Anal Chem 82:9865-9870

16. Solakyildirim K, Zhang Z, Linhardt RJ (2010) Ultraperformance liquid chromatography with electrospray ionization ion trap mass spectrometry for chondroitin disaccharide analysis. Anal Biochem 397:24-28

17. Zhang Z, Xie J, Liu H, Liu J, Linhardt RJ (2009) Quantification of heparan sulfate disaccharides using ion-pairing reversed-phase microflow high-performance liquid chromatography with electrospray ionization trap mass spectrometry. Anal Chem 81: 4349-4355

18. Korir AK, Limtiaco JFK, Gutierrez SM, Larive CK (2008) Ultraperformance ion-pair liquid chromatography coupled to electrospray time-of-flight mass spectrometry for compositional profiling and quantification of heparin and heparan sulfate. Anal Chem 80:1297-1306

19. Oguma T, Tomatsu S, Okazaki O (2007) Analytical method for determination of disaccharides derived from keratan sulfates in human serum and plasma by high-performance liquid chromatography/ turbo-ionspray ionization tandem mass spectrometry. Biomed Chromatogr 21:356-362

20. Oguma T, Tomatsu S, Montana AM, Okazaki O (2007) Analytical method for the determination of disaccharides derived from keratan, heparan, and dermatan sulfates in human serum and plasma by highperformance liquid chromatography/turbo ionspray ionization tandem mass. Anal Biochem 368(1):79-86

21. Yang B, Chang Y, Weyers AM, Sterner ER, Linhardt RJ (2012) Disaccharide analysis of glycosaminoglycan mixtures by ultra-highperformance liquid chromatography-mass spectrometry. J Chromatog A 1225:91-99

22. Galeotti F, Volpi N (2011) Online reverse phase-high-performance liquid chromatography-fluorescence detection-electrospray ionization-mass spectrometry separation and characterization of heparan sulfate, heparin, and low-molecular weight-heparin disaccharides derivatized with 2-aminoacridone. Anal Chem 83:6770-6777

23. Volpi N (2010) High-performance liquid chromatography and online mass spectrometry detection for the analysis of chondroitin sulfates/hyaluronan disaccharides derivatized with 2aminoacridone. Anal Biochem 397:12-23

24. Deakin JA, Lyon M (2008) A simplified and sensitive fluorescent method for disaccharide analysis of both heparin sulfate and chondroitin/dermatan sulfates from biological samples. Glycobiology 18(6):483-491

25. Volpi N, Galeotti F, Yang B, Linhardt RJ (2014) Analysis of glycosaminoglycan-derived precolumn 2-aminoacridone-labeled disaccharides with LC-fluorescence and LC-MS detection. Nat Protoc 9(3):541-558

26. Volpi N, Maccari F, Ferrari S, Luca MD, Pellegrini G (2005) Separation of keratan-sulfate-derived disaccharides by highperformance liquid chromatography and postcolumn derivatization with 2-cyanoacetamide and fluorimetric detection. Anal Biochem 342:200-205

27. Whitham KM, Hadley JL, Morris HG, Andrew SM, Nieduszynski IA, Brown GM (1999) An improved method for the structural profiling of keratan sulfates: analysis of keratan sulfates from brain and ovarian tumors. Glycobiology 9(3):285-291

28. Skidmore MA, Guimond SE, Dumaz-Vorzet AF, Yates EA, Turnbull JE (2010) Disaccharide compositional analysis of heparan sulfate and heparin polysaccharides using UV or high-sensitivity fluorescence (BODIPY) detection. Nat Protoc 5:1983-1992

29. Plaas AHK, Hascall VC, Midura RJ (1996) Ion exchange HPLC microanalysis of chondroitin sulfate: quantitative derivatization of chondroitin lyase digestion products with 2-aminopyridine. Glycobiology 6(8):823-829

30. Chang Y, Yang B, Zhao X, Linhardt RJ (2012) Analysis of glycosaminoglycan-derived disaccharides by capillary electrophoresis using laser-induced fluorescence detection. Anal Biochem 427: 91-98

31. Hitchcock AM, Bowman MJ, Staples GO, Zaia J (2008) Improved workup for glycosaminoglycan disaccharide analysis using capillary electrophoresis with laser-induced fluorescence detection. Electrophoresis 29(22):4538-4548

32. Mitropoulou TN, Lamari F, Syrokou A, Hjerpe A, Karamanos NK (2001) Identification of oligomeric domains within dermatan sulfate chains using differential enzymic treatments derivatization with 2 aminoacridone and capillary electrophoresis. Electrophoresis 22: 2458-2463

33. Zinellu A, Pisanu S, Zinellu E, Lepedda AJ, Cherchi M, Sotgia S, Carru C, Deiana L, Formato M (2007) A novel LIF-CE method for the separation of hyaluronan- and chondroitin sulfate-derived disaccharides: application to structural and quantitative analyses of human plasma low- and high-charged chondroitin sulfate isomers. Electrophoresis 28:2439-2447

34. Kitagawa H, Kinoshita A, Sugahara K (1995) Microanalysis of glycosaminoglycan-derived disaccharides labeled with the fluorophore 2-aminoacridone by capillary electrophoresis and highperformance liquid chromatography. Anal Biochem 232:114-121

35. Militsopoulou M, Lamari FN, Hjerpe A, Karamanos NK (2002) Determination of twelve heparin- and heparan sulfate-derived disaccharides as 2-aminoacridone derivatives by capillary zone electrophoresis using ultraviolet and laser-induced fluorescence detection. Electrophoresis 23:1104-1109

36. Karamanos NK, Hjerpe A (2001) Disaccharide composition in glycosaminoglycans/proteoglycans analyzed by capillary zone electrophoresis. Methods Mol Biol 171:181-192

37. Sato K, Sato K, Okubo A, Yamazaki S (2005) Separation of 2aminobenzoic acid-derivatized glycosaminoglycans and asparaginelinked glycans by capillary electrophoresis. Anal Sci 21(1):21-24 
38. Lamari FN, Militsopoulou M, Mitropoulou TN, Hjerpe A, Karamanos NK (2002) Analysis of glycosaminoglycan-derived disaccharides in biologic samples by capillary electrophoresis and protocol for sequencing glycosaminoglycans. Biomed Chromatogr 16:95-102

39. Rassi ZE, Postlewait J, Mechref Y, Ostrander GK (1997) Capillary electrophoresis of carboxylated carbohydrates. Anal Biochem 244: 283-290

40. Oonuki Y, Yoshida Y, Uchiyama Y, Asari A (2005) Application of fuorophore-assisted carbohydrate electrophoresis to analysis of disaccharides and oligosaccharides derived from glycosaminoglycans. Anal Biochem 343:212-222

41. Plaas AH, West LA, Midura RJ (2001) Keratan sulfate disaccharide composition determined by FACE analysis of keratanase II and endo$\beta$-galactosidase digestion products. Glycobiology 11(10):779-790

42. Yang Y, Breadmore MC, Thormann W (2005) Analysis of the disaccharides derived from hyaluronic acid and chondroitin sulfate by capillary electrophoresis with sample stacking. J Sep Sci 28(17): 2381-2389
43. Xia B, Kawar ZS, Ju T, Alvarez RA, Sachdev GP, Cummings RD (2005) Versatile fluorescent derivatization of glycans for glycomic analysis. Nat Methods 2(11):845-850

44. Pomin VH, Piquet AA, Pereira MS, Mourão PAS (2012) Residual keratan sulfate in chondroitin sulfate formulations for oral administration. Carbohydr Polym 90:839-846

45. Galeotti F, Maccari F, Volpi N (2014) Selective removal of keratan sulfate in chondroitin sulfate samples by sequential precipitation with ethanol. Anal Biochem 448:113-115

46. Arnett SD, Lunte CE (2007) Enhanced pH-mediated stacking of anions for capillary. Electrophoresis 28(20):3786-3793

47. Funderburgh JL (2000) Keratan sulfate: structure, biosynthesis, and function. Glycobiology 10(10):951-958

48. Weyers A, Yang B, Solakyildirim K, Yee V, Li L, Zhang F, Linhardt RJ (2013) Isolation of bovine corneal keratan sulfate and its growth factor and morphogen binding. FEBS J 280:2285-2293

49. Zhao X, Yang B, Datta P, Gasmili L, Zhang F, Linhardt RJ (2012) Cell-based microscale isolation of glycoaminoglycans for glycomics study. Carbohydr Chem 31(4-6):420-435 